\title{
O CONCEITO DE GÊNERO TEXTUAL E O TRABALHO COM DIFERENTES TIPOS DE TEXTOS EM SALA DE AULA
}

\author{
THE CONCEPT OF TEXTUAL GENRE AND THE WORK \\ WITH DIFFERENT TYPES OF TEXTS IN A CLASSROOM
}

\section{Vaneide Correa DORNELLAS ${ }^{1}$}

\begin{abstract}
RESUMO: O presente artigo tem o objetivo de realizar uma reflexão sobre o trabalho com gêneros textuais em sala de aula, a partir dos estudos realizados pelo Grupo de Estudos da Alfabetização Inicial (GEAI), formado por professores alfabetizadores da Escola de Educação Básica da Universidade Federal de Uberlândia (ESEBA/UFU), sobre o volume $n^{\circ} 5$ dos Cadernos de Formação do Pacto Nacional pela Alfabetização na Idade Certa (PACTO). A escola deve possibilitar o acesso do educando às diversas formas textuais que circulam na sociedade com o objetivo de ensiná-los a compreendê-las e produzi-las. Acredita-se que o trabalho em sala de aula com diferentes gêneros pode ser um recurso significativo para o processo de ensino e aprendizagem no espaço escolar, pois tem a possibilidade de permitir e facilitar o desenvolvimento de habilidades orais e escritas dos alunos, conduzindo-os a adquirir uma visão real do funcionamento social da linguagem.
\end{abstract}

Palavras-chaves: Gêneros, Suportes, Texto.

ABSTRACT: This article aims to draw a reflection on working with text genres in the classroom, from the studies conducted by the Grupo de Estudos da Alfabetização Inicial - GEAI, formed by Basic Education school teachers at the Federal University of UberlândiaESEBA/UFU, about volume No.5 of the National Pact for Literacy at the Right Age formation books. The school must allow the learners to access various textual forms that circulate in society in order to teach them to understand and produce these texts. It is believed that work in the classroom with different genres can be a significant resource for the teaching and learning process in the school space, because it

1 Mestre em Educação pela Universidade Federal de Uberlândia, docente da Educação Infantil do Colégio de Aplicação (CapEseba/UFU) da Universidade Federal de Uberlândia. 
has the ability to enable and facilitate the development of the students' oral and written skills, leading them to acquire a real vision of the social functioning of language.

Keywords: genres, formats, text.

\section{INTRODUÇÃO}

Este texto tem o objetivo de apresentar análises de estudo dos Cadernos de Formação do Pacto Nacional pela Alfabetização na Idade Certa $\left(\mathrm{PACTO}^{2}\right)$, de Língua Portuguesa, das Unidades 5, dos anos 1, 2 e 3, intitulados, respectivamente:

1. Os diferentes textos em sala de alfabetização;

2. O trabalho com gêneros textuais na sala de aula;

3. O trabalho com diferentes gêneros textuais na sala de aula: diversidade e progressão escolar andando juntas.

O presente artigo pretende aprofundar o estudo sobre os gêneros textuais na alfabetização, pois se acredita que a discussão sobre essa temática pode contribuir para que os profissionais da educação percebam as contribuições de

${ }^{2}$ A palavra PACTO, em maiúscula, será apresentada ao referir-se ao Pacto Nacional pela Alfabetização na Idade Certa, por considerar a convenção nacional. 
uma prática docente que privilegia 0 trabalho com diferentes textos em sala de aula.

Por todos os lugares em que as pessoas passam, nas ruas, nas praças, na escola, ou em casa, se deparam com uma grande quantidade de diferentes textos, orais ou escritos, como: narração de jogos, diário, reportagens, conversas ao telefone, lista de compras, apresentação de um trabalho escolar, conversa informal com um colega ou familiar, receita culinária, bula de remédio, carta, bilhete, e-mail, manual de instruções, entre vários outros. Todos esses são exemplos de gêneros textuais, ou seja, as formas naturais em que utilizamos a língua, e, para cada situação de comunicação que acontece no nosso cotidiano, é utilizado um gênero textual. Essas situações devem ser utilizadas em sala de aula e, por isso, este texto relaciona algumas possibilidades desse uso.

A primeira parte deste trabalho apresenta uma discussão teórica sobre o que são gêneros textuais e suas possibilidades de trabalho em sala de aula. Na sequência, tais possibilidades são relacionadas às experiências 
apresentadas pelo PACTO por meio dos Cadernos de Formação das Unidades 5 (anos 1, 2 e 3).

Para entender melhor a relação do tema com as orientações nesses Cadernos de Formação, deve-se esclarecer que o PACTO é um compromisso formal assumido pelo governo federal, do Distrito Federal, dos estados e dos municípios de assegurar que todas as crianças sejam alfabetizadas até os oito anos de idade, isto é, ao final do $3^{\circ}$ ano do Ensino Fundamental.

De acordo com os documentos do PACTO, aos oito anos de idade, as crianças já precisam ter o entendimento e a compreensão do funcionamento do sistema de escrita e o domínio das correspondências grafofônicas, mesmo que não dominem todas as convenções ortográficas irregulares; além de fluência de leitura e domínio de estratégias de compreensão e de produção de textos escritos. Dentro da visão de alfabetização apresentada nos Cadernos de Formação do PACTO, o professor alfabetizador tem a função de auxiliar na formação para o bom exercício da cidadania. Para isso, precisa entender a alfabetização para além de uma visão tradicional que considera a aquisição da 
leitura e a produção de texto como uma aprendizagem de habilidades individuais de simples codificação e decodificação.

Assim, a alfabetização deve ser um processo significativo para o aluno e deve levar em consideração seus conhecimentos prévios e experiências de seu cotidiano. Precisa, ainda, abarcar os conceitos de letramento que têm como objeto de aprendizagem os aspectos sociais da língua escrita.

Nesse sentido, é fundamental que os professores alfabetizadores planejem ações que contribuam para melhorar a qualidade do ensino nos anos iniciais e que possibilitem aos alunos aprendizagens significativas, as quais são o elemento essencial ao processo de aquisição do conhecimento, segundo Ausubel (1980). De acordo com o autor, para que o aluno aprenda, a informação que recebe precisa fazer algum sentido para ele, dentro do processo de aquisição do conhecimento. Dessa forma, essa informação deverá ancorar-se em conceitos relevantes já existentes na estrutura do aluno (MOREIRA, 2001). Portanto, faz-se necessário que o professor proponha a 
seus alunos leitura e produção textual de temas ligados ao cotidiano deles, para que compreendam a importância social da leitura e da escrita. Além disso, o professor deve valorizar e acolher a bagagem cultural diversificada que os alunos possuem, independentemente da escola, pois eles já são participantes de atividades nos grupos sociais a que pertencem, portanto, trazem para a escola conhecimentos prévios de diversos gêneros textuais.

\section{OS GÊNEROS TEXTUAIS NA SALA DE}

\section{AULA}

Ao realizarem atividades referentes aos gêneros textuais utilizados em seu dia a dia, os alunos têm oportunidade de terem acesso a um trabalho significativo, pois convivem com a necessidade da comunicação por meio da escrita. Nesse sentido, o conhecimento prévio é fundamental para que, a partir dele, situações de aprendizagem possam ser criadas e, consequentemente, haja o avanço na escrita dos alunos.

De acordo com Brasil (2012a), 
O acesso à diversidade de gêneros que circulam em diferentes esferas sociais favorece o ingresso das crianças no mundo da escrita e sua participação em situações mais públicas de uso da oralidade. No entanto, para que os meninos e as meninas possam participar das diferentes situações de interação não é suficiente ter contato com os textos, eles precisam desenvolver autonomia de leitura e escrita. (BRASIL, 2012a, p. 7).

É realidade que os gêneros textuais, cada vez mais, passam a nortear o trabalho em salas de aula nas atividades de análise, interpretação e produção de textos, no intuito de favorecer o desenvolvimento da competência linguística e discursiva do aluno, como também indicam os cadernos do PACTO. Mas, para entender melhor como vem sendo o processo dessa prática, faz-se necessário um pequeno retorno ao pensamento de estudiosos da educação há três décadas.

A partir da década de 80 , muitos trabalhos e pesquisas começaram a surgir com a temática relacionada ao processo de ensino e de aprendizagem da leitura e da escrita sob a égide da psicogênese da língua escrita difundida no Brasil, principalmente a partir das ideias apresentadas por Emília Ferreiro e Ana Teberosky (1985). Com base nos resultados dessas pesquisas, muitos 
educadores passaram a compreender, de forma diferente de como entendiam antes, "como se dá a aquisição da aprendizagem de leitura e escrita pelas crianças" e a repensarem suas práticas de alfabetização.

Na década de 90, Magda Soares (1998) amplia o termo alfabetização e designa novas práticas de leitura e escrita abarcando o conceito de letramento, que compreende tanto a apropriação das técnicas de alfabetização quanto o convívio e hábito de utilização da leitura e escrita no cotidiano dos alunos. De acordo com a autora, o letramento aparece sempre ligado à compreensão da leitura e da escrita como práticas sociais que privilegiam a visão da língua que usamos a todo o momento em que nos comunicamos. Soares (1998) destaca a importância de o aluno ser alfabetizado em um contexto em que a leitura e a escrita tenham sentido para o educando. O contexto em que o aluno está inserido, portanto, é de extrema relevância. 
Em uma perspectiva sociointeracionista ${ }^{3}$, preconizada por estudiosos da educação nas décadas de 1980 e 1990 no Brasil, os eixos centrais do ensino da língua são a compreensão e a produção de textos. Porém, é necessário que estejam de acordo com a realidade cultural e social em que os alunos vivem. Em uma situação de letramento, o estudo da língua deve se configurar como uma forma de ação do indivíduo no meio em que vive, dentro de seu contexto histórico. Nesse sentido, a escolha de textos a serem trabalhados na sala de aula deve acontecer de acordo com os gêneros textuais encontrados nas interações sociais dos alunos. Durante a década de 90, no Brasil, várias foram as tentativas de educadores a favor de uma educação mais centrada nas experiências e relações dos discentes.

A partir de 1995, por exemplo, o Governo Federal começou a elaborar um documento, divulgado em 1997 como Parâmetros Curriculares Nacionais (PCNs), que

\footnotetext{
${ }^{3}$ A abordagem sociointeracionista concebe a aprendizagem como um fenômeno que se realiza na interação com o outro. A aprendizagem acontece por meio da internalização, a partir de um processo anterior, de troca, que possui uma dimensão coletiva.
} 
passou a servir como referencial para os Ensinos Fundamental e Médio de todo o país com o intuito de garantir a todas as crianças e jovens, mesmo em condições socioeconômicas desfavoráveis, o direito ao acesso a um conjunto de conhecimentos reconhecidos como necessários para o exercício da cidadania. Os PCNs da Língua Portuguesa estão fundamentados em uma teoria de gêneros textuais e sugerem, na sala de aula, a expansão das várias possibilidades do uso da linguagem já usadas pelos alunos nas suas atividades comunicativas cotidianas dentro e fora da escola.

Diante do exposto, é possível perceber que a preocupação com os textos que fazem parte da vida dos educandos, ou seja, com os diferentes tipos de gêneros textuais, não é nova. Entretanto, sua importância tem se intensificado cada vez mais nos últimos anos, principalmente nos materiais de formação de professores. A referência aos gêneros diz respeito a textos orais e escritos utilizados pelas pessoas nas diversas atividades comunicativas. Essas atividades se fazem presentes nas práticas discursivas da vida das pessoas nos diferentes 
âmbitos sociais em que estão inseridas. Esses textos (orais e escritos) se definem por sua composição, seu estilo e objetivos de comunicação.

Atualmente, a noção de gênero, que embasa as ações em prol do letramento, tem se pautado nas considerações de Marcuschi (2008, p. 147), que o define como "uma categoria distintiva de discurso de qualquer tipo, falado ou escrito, com ou sem aspirações literárias". Assim, a noção contribui para entender a língua não só em seu aspecto formal e estrutural, mas, primordialmente, como uma forma de ação social, histórica e cognitiva. Como já foi dito antes, os gêneros textuais fazem parte de todas as situações de comunicação que ocorrem no nosso dia a dia e para cada situação existe um gênero textual a ser explorado.

As designações usadas para os gêneros não são uma invenção pessoal, mas uma denominação histórica e socialmente construída. Mesmo assim, é difícil determinar o nome de cada gênero textual, geralmente, os nomes partem de algum critério. Para melhor compreensão dos gêneros textuais, Bahktin (1997) propõe dividi-los e 
exemplificá-los em gêneros primários e secundários, conforme o uso que se faz da linguagem, o contexto onde essa linguagem acontece e os interlocutores. Por gêneros textuais primários entendem-se os gêneros do cotidiano que não precisam ser ensinados, pois são aprendidos na interação com as outras pessoas, como uma lista de compras, uma conversa ao telefone e um bilhete. Eles se constroem em situações espontâneas de uso da linguagem.

Já os gêneros secundários precisam ser ensinados e aprendidos, geralmente na escola, e se caracterizam pela forma padronizada de organização da linguagem, como a escrita de um livro, de uma reportagem, uma palestra ou um noticiário. Segundo Bakhtin (1977), os gêneros podem ser aprendidos espontaneamente, na convivência e socialização com o outro, e é por meio deles que a comunicação se torna possível. Para Bakhtin (1977),

Aprendemos a moldar nossa fala às formas do gênero e, ao ouvir a fala do outro, sabemos de imediato, bem nas primeiras palavras, pressentir-lhe 0 gênero, adivinhar-Ihe 0 volume (a extensão aproximada do todo discursivo), a dada estrutura composicional, prever-Ihe o fim. (...) Se não existissem os gêneros do discurso e se não os 
dominássemos, se tivéssemos de construir cada um de nossos enunciados, a comunicação verbal seria quase impossível. (BAKHTIN, 1977, p. 302).

É relevante também definir que os gêneros podem ser escritos e falados. Para exemplificar a diferença entre os gêneros textuais que abordam a linguagem oral e a escrita, é exposto abaixo o quadro de gêneros previstos para a prática de compreensão de textos, presente nos Parâmetros Curriculares Nacionais de Língua Portuguesa.

Quadro 1. Gêneros previstos para a prática de compreensão de textos.

\begin{tabular}{|c|c|c|c|}
\hline \multicolumn{4}{|c|}{ GENEROS PREVISTOS PARAA PRÁTICA DE COMPRENSÃO DE TEXTOS } \\
\hline \multicolumn{2}{|c|}{ LINGUAGEM ORAL } & \multicolumn{2}{|c|}{ LINGUAGEM ESCRITA } \\
\hline LITERARIOS & $\begin{array}{l}\text { Cordel } \\
\text { Texto dramático }\end{array}$ & LITERARIOS & $\begin{array}{l}\text { Conto } \\
\text { Novela } \\
\text { Romance } \\
\text { Crônica } \\
\text { Poema } \\
\text { Texto dramático }\end{array}$ \\
\hline DE RMPRENSA & $\begin{array}{l}\text { Comentário } \\
\text { radiofônico } \\
\text { Entrevista } \\
\text { Debate } \\
\text { Depoimento }\end{array}$ & DE MMPRENSA & $\begin{array}{l}\text { Notícia } \\
\text { Editorial } \\
\text { Artigo } \\
\text { Reportagem } \\
\text { Carta do leitor } \\
\text { Entrevista }\end{array}$ \\
\hline $\begin{array}{l}\text { DE DIVULGAÇÃO } \\
\text { CENTÍFICA }\end{array}$ & $\begin{array}{l}\text { Exposição } \\
\text { Seminário } \\
\text { Debate } \\
\text { Palestra }\end{array}$ & $\begin{array}{l}\text { DE DIVULGAÇÃO } \\
\text { CIENTÍFICA }\end{array}$ & $\begin{array}{l}\text { Verbete enciclopédico } \\
\text { (nota / artigo) } \\
\text { Relatório de experiências } \\
\text { Didático (textos, Enunciados de } \\
\text { questóes) }\end{array}$ \\
\hline
\end{tabular}

Fonte: Parâmetros Curriculares Nacionais da Língua Portuguesa (1997), p.40. 
Faz-se necessária, ainda, a diferenciação entre gêneros textuais e tipos textuais. Variadas são as intenções de um texto e ele pode ser produzido em diversas situações. Portanto, é preciso analisar os elementos que o compõem, como: em que situação foi escrito? Quem escreveu? Para quem escreveu? Quais os objetivos dessa escrita?

Essa análise leva à reflexão da finalidade do texto, pois, dependendo da sua função, será usado o gênero textual mais conveniente para cada situação. Por exemplo, se a intenção do autor for contar uma história ou apresentar uma sequência de fatos, o gênero textual usado para tal fim poderá ser um romance, uma fábula ou uma carta. Mas, se a intenção for de dar uma informação, instruir ou ensinar algo, o gênero textual utilizado deverá ser uma notícia, um manual de instruções ou uma receita culinária.

Segundo Günther (1991, p. 400 apud MARCUSCHI, 2008, p. 171), "um gênero que pode ser usado para servir a uma certa função interativa em nossa cultura pode se tornar inadequado numa situação cultural diferente". 
Portanto, pode-se concluir que o uso que se faz de cada gênero se encontra relacionado ao aspecto sociocultural do contexto em que é apresentado. Nesse aspecto, um texto pode ter diversas funções.

Em relação à função de um texto, os gêneros textuais estão divididos em diferentes tipos textuais. A análise de seu uso e aplicação leva ao conceito de tipos textuais, que se referem, portanto, à finalidade. Não são textos com funções sociais definidas; mas, sim, categorias teóricas. Os tipos textuais não mudam, já estão determinados e se dividem em cinco tipos, de acordo com Werlich (1973), citados por Marcuschi (2002, p.26-28):

1- Narrativo;

2-Descritivo;

3- Argumentativo;

4- Explicativo ou expositivo;

5- Instrucional ou injuntivo.

O tipo textual narrativo é marcado pela temporalidade. Descreve um fato ou uma ação, por isso, a progressão temporal é essencial para o seu desenrolar, 
visto que é necessário ter um determinado lugar e tempo para acontecer.

O tipo textual descritivo é marcado pela espacialidade. Não tem uma sucessão dentro de um tempo demarcado, mas, sim, a apresentação de uma imagem que reproduz um momento. Já nos textos de tipo textual argumentativo se faz a defesa de um ponto de vista, ideia ou questionamento de um fato. Requer uma ideia mais objetiva, pois o propósito é convencer o leitor ou ouvinte, fundamentando-se em argumentos.

O tipo textual explicativo ou expositivo tem como escopo explicar ou dar informações a respeito de algo para que o leitor adquira um conhecimento. Não há, nesses tipos de texto, a defesa de uma ideia, mas, sim, a identificação de um fenômeno, conceito ou definição.

O tipo textual instrucional ou injuntivo tem como objetivo dar instruções e está pautado nas explicações e no método. Geralmente, esse tipo textual se caracteriza por construções frasais iniciadas por um verbo no infinitivo ou outras formas que indicam orientação ou ordem. Saber definir a função dos tipos textuais é imprescindível para um 
trabalho consciente por parte do professor a favor da aprendizagem do aluno.

O conhecimento das possibilidades de uso de gêneros textuais é muito útil ao professor, pois o auxiliará a escolher qual deles se adéqua mais à sua intenção de análise, compreensão e construção de textos pelos alunos. Deve-se ter clareza de que, dependendo da finalidade do texto (tipo textual), é que deve ser escolhido o gênero textual a ser trabalhado em sala de aula.

Marcuschi (2008, p. 159) afirma que "gêneros e tipos não são opostos, não formam uma dicotomia. São complementares e integrados, são formas constitutivas do texto em funcionamento". Para melhor compreensão, Marcuschi (2002) faz uma distinção entre gênero textual e tipo textual da seguinte forma:

(a) Usamos a expressão tipo textual para designar uma espécie de construção teórica definida pela natureza lingüística de sua composição (aspectos lexicais, sintáticos, tempos verbais, relações lógicas). Em geral, os tipos textuais abrangem cerca de meia dúzia de categorias conhecidas como: narração, argumentação, exposição, descrição, injunção. (b) Usamos a expressão gênero textual como uma noção propositalmente vaga para referir os textos materializados que encontramos em 
nossa vida diária e que apresentam características sócio-comunicativas definidas por conteúdos, propriedades funcionais, estilo e composição característica. Se os tipos textuais são apenas meia dúzia, os gêneros são inúmeros. Alguns exemplos de gêneros textuais seriam: telefonema, sermão, carta comercial, carta pessoal, romance, bilhete, reportagem jornalística, aula expositiva, reunião de condomínio, notícia jornalística, horóscopo, receita culinária, bula de remédio, lista de compras, cardápio de restaurante, instruções de uso, outdoor, inquérito policial, resenha, edital de concurso, piada, conversação espontânea, conferência, carta eletrônica, bate-papo por computador, aulas virtuais e assim por diante. (Marcuschi, 2002, p. 22).

O quadro abaixo, proposto neste artigo, apresenta as possibilidades de uso de gêneros adequados aos diferentes tipos textuais.

Quadro 2. Possibilidades de uso de gêneros adequados aos diferentes tipos textuais.

\begin{tabular}{|l|l|l|}
\hline TIPO TEXTUAL & \multicolumn{1}{|c|}{ FUNÇÃO } & \multicolumn{1}{|c|}{$\begin{array}{c}\text { EXEMPLOS DE } \\
\text { GÊNERO TEXTUAL }\end{array}$} \\
\hline NARRATIVO & $\begin{array}{l}\text { Contar uma história } \\
\text { ou apresentar uma } \\
\text { sequência de fatos. }\end{array}$ & $\begin{array}{l}\text { crônica, romance, conto } \\
\text { de fada, fábula, lenda, } \\
\text { piada, carta, bilhete, } \\
\text { novela, histórias, casos } \\
\text { contados entre amigos, } \\
\text { notícia, reportagem. }\end{array}$ \\
\hline DESCRITIVO & $\begin{array}{l}\text { Enumerar lancíncio, classificados, } \\
\text { características de } \\
\text { fatos, lugares, } \\
\text { pessoas e ações. }\end{array}$ & $\begin{array}{l}\text { lista de ingredientes, } \\
\text { guia turístico, lista de } \\
\text { compras, legenda, } \\
\text { biografia, notícia, }\end{array}$ \\
\hline
\end{tabular}




\begin{tabular}{|c|c|c|}
\hline & & $\begin{array}{l}\text { reportagem, diário, } \\
\text { relato de viagem, relato } \\
\text { policial. }\end{array}$ \\
\hline ARGUMENTATIVO & $\begin{array}{l}\text { Discutir questões, } \\
\text { defender um ponto } \\
\text { de vista. }\end{array}$ & $\begin{array}{l}\text { redações monográficas, } \\
\text { críticas, artigo de } \\
\text { opinião, debate, carta } \\
\text { de reclamação, carta de } \\
\text { leitor, ensaio. }\end{array}$ \\
\hline EXPLICATIVO & $\begin{array}{l}\text { Transmitir } \\
\text { informações. }\end{array}$ & $\begin{array}{l}\text { capítulo de livro } \\
\text { didático, verbetes de } \\
\text { dicionários, } \\
\text { enciclopédias, } \\
\text { conferência, seminário, } \\
\text { palestras, notícias } \\
\text { jornalísticas. }\end{array}$ \\
\hline INSTRUCIONAL & $\begin{array}{l}\text { Transmitir } \\
\text { informações e } \\
\text { prescrições de ação. }\end{array}$ & $\begin{array}{l}\text { bula de remédio, } \\
\text { propaganda, receita } \\
\text { culinária, manual de } \\
\text { instruções } \\
\text { montagem ou uso de } \\
\text { um aparelho, } \\
\text { regimentos, regras de } \\
\text { jogo, regras de trânsito, } \\
\text { leis. }\end{array}$ \\
\hline
\end{tabular}

Fonte: Adaptado de Dolz e Schneuwly (2004).

Os Cadernos de Língua Portuguesa do PACTO, nas Unidades 5, não apresentam a diferenciação entre os gêneros textuais e os tipos textuais, apesar de ter sido comentado, no caderno do ano 2 (Brasil, 2012c, p.7), que se referem a "tipos textuais para tratarmos de sequências teoricamente definidas pela natureza linguística da sua composição: narração, exposição, argumentação, descrição, injunção". Porém, no caderno do ano 3 (Brasil, 
2012d, p. 8-9) há um quadro que agrupa 11 grupos de gêneros semelhantes e diferentes entre si e uma argumentação, segundo os autores, de que os alunos precisam reconhecer e compreender seus usos e suas finalidades e enfatiza que os grupos de 1 ao 5 têm especial importância no ciclo de alfabetização.

Quadro 3 - Grupos de gêneros semelhantes e diferentes.

\begin{abstract}
1) Textos literários ficcionais
São textos voltados para a narrativa de fatos e episódios do mundo imaginário (não real). Entre estes, podemos destacar contos, lendas, fábulas, crônicas, obras teatrais, novelas e causos.

2) Textos do patrimônio oral, poemas e letras de músicas

Os textos do patrimônio oral, logo que são produzidos têm autoria, mas, depois sem um registo escrito, tornam-se anônimos, passando a ser patrimônio da comunidades. São exemplos: as travalínguas, parlendas, quadrinhas, adivinhas, provérbios. Também fazem parte do segundo agrupamento os poemas e as letras de músicas.

3) Textos com a finalidade de registrar e analisar as ações humanas individuais e coletivas e contribuir para que as experiências sejam guardadas na memóri das pessoas

Tais textos analisam e narram situaçõe vivenciadas pelas sociedades, tais como a biografias, testemunhos orais e escritos, obras historiográficas e noticiários.

4) Textos com a finalidade de construir e fazer circular entre as pessoas o conhecimento escolar/científico

São textos mais expositivos, que socializam informaçōes, por exemplo, as notas de enciclopédia, os verbetes de dicionário,
\end{abstract}

os seminários orais, os textos didáticos,

os relatos de experiências científicas e os textos de divulgação científica.

5) Textos com a finalidade de debater temas que suscitam pontos de vista diferentes, buscando o convencimento do outro

Com base nos textos do agrupamento 5 os sujeitos exercitam suas capacidades argumentativas. Cartas de reclamação, cartas de leitores, artigos de opinião, editoriais, debates regrados e reportagens

são exemplos de textos com tais finalidades.

6) Textos com a finalidade de divulgar produtos e/ou serviços - e promover campanhas educativas no setor da publicidade

Também aqui a persuasão está presente, mas com a finalidade de fazer o outro adquirir produtos e/ou serviços ou mudar determinados comportamentos. São exemplos: cartazes educativos, anúncios publicitários, placas e faixas.

7) Textos com a finalidade de orientar e prescrever formas de realizar atividades diversas ou formas de agir em determinados eventos

Fazem parte do grupo sete os chamados textos instrucionais, tais como as receitas, os manuais de uso de eletrodomésticos, as instruções de jogos, as instruçōes de montagem e os regulamentos.
8) Textos com a finalidade de orientar a organização do tempo e do espaço nas atividades individuais e coletivas necessárias à vida em sociedade.

São eles: as agendas, os cronogramas, os calendários, os quadros de horários, as folhinhas e os mapas.

9) Textos com a finalidade de mediar as ações institucionais.

São textos que fazem parte, principalmente, dos espaços de trabalho: os requerimentos, os formulários, os ofícios, os currículos e os avisos.

10) Textos epistolares utilizados para as mais diversas finalidades

As cartas pessoais, os bilhetes, os e-mails, os telegramas medeiam as relações entre as pessoas, em diferentes tipos de situaçōes de interação.

11) Textos não verbais

Os textos que não veiculam a linguagem verbal, escrita, tendo, portanto, foco na linguagem não verbal, tais como as histórias em quadrinhos só com imagens, as charges, pinturas, esculturas e algumas placas de trânsito compõem tal agrupamento.

Fonte: Brasil, 2012d, Caderno no 5, ano 3, p. 8-9.

O quadro mostra diferentes tipos de textos que devem

ser trabalhados em sala. Outro ponto importante que é preciso esclarecer quando se trata de gêneros textuais é a forma de apresentação dos textos. Esse é um ponto 
essencial para que o aluno entenda como o texto circula na sociedade e, em alguns casos, a sua importância. Essa apresentação diz respeito ao que é chamado de suporte. Para Marcuschi (2003, p. 11), a noção de suporte relaciona-se à ideia de um "portador do texto", entendido como "um lócus físico ou virtual com formato específico que serve de base ou ambiente de fixação do gênero materializado como texto".

Podemos dizer, então, que suporte textual é o lugar onde os gêneros são colocados para circular. Os suportes tanto amparam uma mensagem quanto auxiliam e, às vezes, até definem a mensagem do que está escrito - um texto, com uma mesma mensagem, pode ser mudado dependendo de seu suporte. A ideia da apresentação de um mesmo produto, por exemplo, deve ter o texto alterado dependendo se seu suporte é um outdoor ou uma revista.

É importante, inclusive, que o professor leve o texto para sala de aula em seu suporte autêntico. Por exemplo, se decidir levar uma reportagem jornalística para trabalhar alguma atividade em sala é interessante que mostre o jornal, se levar uma história em quadrinhos deve 
apresentar o gibi de onde foi retirado. Também é importante mencionar que um mesmo suporte pode veicular diversos gêneros textuais, como uma revista. São exemplos de suportes: livro, livro didático, jornal (diário), revista (semanal/mensal), revista científica (boletins e anais), rádio, televisão, telefone, quadro de avisos, outdoor, encarte, folder, luminosos, faixas, embalagens, roupas, paredes, muros, entre outros.

Os cadernos do PACTO também não esclarecem sobre os suportes textuais, apesar de incentivar o professor a buscar e usar esses suportes. Inclusive, sugere o uso de vários livros literários a respeito dos assuntos e projetos abordados. Na verdade, o objetivo dos cadernos mencionados neste artigo é sugerir práticas pedagógicas que privilegiem o uso de gêneros textuais em sala de aula, em maior número possível, por meio de relatos de experiências de professores de escolas públicas de vários lugares.

Primeiramente, é apresentado um relato de experiência de algum professor em sua prática docente, no desenvolvimento de alguma aula ou projeto. Depois, 
especialistas em Educação dão sugestões de ações pedagógicas e atividades que poderiam ser inseridas nessa aula. Dessa forma, as aulas são refletidas e analisadas levando em consideração uma perspectiva sociointeracionista, que busca um ensino que deve propiciar ao aluno o uso da linguagem, considerando os diferentes contextos em que ela é utilizada. Nesse sentido, os autores dão sugestões de atividades que poderiam ser acrescentadas, questões a serem discutidas com os alunos, sugestões de obras complementares e sugestões de leituras para orientação do trabalho do professor.

De acordo com os autores, a escolha dos textos a serem trabalhados não deve estar centrada apenas na apropriação do Sistema da Escrita Alfabética (SEA), mas, também, na capacidade de compreensão e produção de textos pelos alunos. E há também uma preocupação em integrar diferentes componentes curriculares. Para tanto, faz-se necessário que o professor pense em situações diversificadas de leitura e escrita com textos de diferentes gêneros, de modo a desenvolver diferentes capacidades e conhecimentos. 


\section{ANÁLISE DOS CADERNOS DE LÍNGUA}

\section{PORTUGESA}

A Unidade 5 do ano 2 (Brasil, 2012c) analisa o registro de situações pedagógicas sob a justificativa de mostrar como um trabalho pode ser aprofundado na escola para o estudo de um gênero textual, a fim de desenvolver conhecimentos e capacidades para a compreensão e produção de textos. Um exemplo desse registro é uma análise da prática no $2^{\circ}$ ano do Ensino Fundamental da professora Rielda Karyna Albuquerque, na Escola Ubaldino Figueirôa, situada em Jaboatão dos Guararapes/PE. Nessa análise, há o incentivo ao diálogo entre professores e alunos, além da sugestão da participação ativa dos educandos, para desenvolver habilidades argumentativas deles.

Na Unidade 5 do ano 3 (Brasil, 2012d) são apresentadas algumas estratégias para a seleção e a utilização de textos de diferentes gêneros em turmas de 
alfabetização, como o quadro 3 deste artigo, com os 11 grupos de gêneros. Devido à multiplicidade de gêneros, a escola não tem condições de trabalhar todos durante os três anos de alfabetização. Mas não se trata de escolher qual é menos ou mais importante, a questão é trabalhar conforme a necessidade e habilidades a serem desenvolvidas em cada período. Isso não quer dizer que um gênero tem que ser trabalhado em um ano específico, mas os gêneros devem corroborar para que os objetivos didáticos sejam aprofundados. Com isso, a abordagem adotada em cada ano deve ter gradativamente sua complexidade aumentada. O trabalho progressivo com os gêneros exige que o professor conheça as habilidades que seus alunos possuem e estabeleça quais devem ser desenvolvidas e/ou aprofundadas.

\section{CONSIDERAÇÕES FINAIS}

A diversidade dos gêneros deve ser explorada pela escola porque cada gênero, com sua especificidade, pode proporcionar diferentes aprendizagens. Eles não podem ser 
trabalhados todos ao mesmo tempo. É necessário encontrar - melhor momento e oportunidade de aplicação e exploração de determinado gênero textual, a fim de oferecer, ao aluno, a oportunidade de diferentes práticas de letramento. Entretanto, é importante que em todas as etapas de alfabetização e letramento sejam trabalhados os diferentes gêneros textuais.

Recentemente, muito se tem discutido sobre as dificuldades e problemas enfrentados pelos alunos das escolas públicas em relação ao domínio da leitura e da escrita. Um dos grandes desafios para as políticas públicas educacionais é a formação dos professores, a fim de caminhar em uma perspectiva de construção de práticas, que contemplem 0 desenvolvimento de diferentes habilidades e capacidades dos alunos, em fase de alfabetização.

É nesse sentido que os Cadernos de Formação do PACTO trazem um enfoque de articulação entre apropriação do SEA, oralidade, leitura, produção textual e análise linguística. Além de preconizar a alfabetização por meio do letramento e a integração dos diversos componentes 
curriculares, destaca a necessidade de trabalhar com a diversidade de gêneros textuais, a fim de que o educando tenha uma aprendizagem significativa, por se tratar de conteúdos vivenciados em seu contexto social e cultural.

\section{BIBLIOGRAFIA}

AUSUBEL, D.P.; NOVAK, J.D. e HANESIAN, H. Psicologia educacional. Rio de Janeiro, Interamericana. Tradução para português de Eva Nick et al., da segunda edição de Educational psychology: a cognitive view, 1980.

BAKHTIN, Mikhail. Estética da criação verbal. São Paulo: Martins Fontes, 1997.

BRASIL. Parâmetros Curriculares Nacionais: Língua Portuguesa. Brasília: MEC/SEF, 1997.

- Pacto Nacional pela Alfabetização na Idade Certa: Formação do Professor Alfabetizador. Caderno de Apresentação. Ministério da Educação, Secretaria de Educação Básica, Diretoria de Apoio à Gestão Educacional. Brasília: MEC/SEB, 2012a.

- Pacto Nacional pela Alfabetização na Idade

Certa: Os Diferentes Textos em Sala de Alfabetização. Ano: 1, unidade 5. Ministério da Educação, Secretaria de Educação Básica, Diretoria de Apoio à Gestão Educacional. Brasília: MEC/SEB, 2012b.

\section{- Pacto Nacional pela Alfabetização na Idade}

Certa: O Trabalho com Gêneros Textuais na Sala de Aula. Ano: 2, unidade 5. Ministério da Educação, Secretaria de Educação Básica, Diretoria de Apoio à Gestão Educacional. Brasília: MEC/SEB, 2012c. 
- Pacto Nacional pela Alfabetização na Idade

Certa: O Trabalho com Diferentes Gêneros Textuais na Sala de Aula: diversidade e progressão escolar andando juntas. Ano: 3, unidade 5. Ministério da Educação, Secretaria de Educação Básica, Diretoria de Apoio à Gestão Educacional. Brasília: MEC, SEB, 2012d.

FERREIRO, Emília e TEBEROSKY, Ana. Psicogênese da Língua Escrita. Porto Alegre: ArtMed, 1985.

MARCUSCHI, Luiz Antônio. A produção Textual, Análise de Gêneros e Compreensão. São Paulo: Parábola Editorial, 2008.

. A questão do suporte dos gêneros textuais. DLCV:

Língua, Linguística e Literatura, João Pessoa, v. 1, n. 1, 2003, p. 9-40.

. Gêneros Textuais: Definição e Funcionalidade: In DIONÍSIO, Ângela Paiva; MACHADO, Ana Rachel; BEZERRA, Maria Auxiliadora (Orgs.). Gêneros Textuais \& Ensino. Rio de Janeiro: Lucerna, 2002.

MOREIRA, M.A. e MASINI, Elcie F. Salzano. Aprendizagem significativa: a teoria de David Ausubel. São Paulo: Centauro, 2001.

SCHNEUWLY, Bernard; DOLZ, Joaquim e colaboradores. Gêneros orais e escritos na escola. São Paulo: Mercado das Letras, 2004.

SOARES, Magda Becker. Letramento: um tema em três gêneros. Belo Horizonte: Autêntica, 1998. 